\title{
Hydraulic conductance of two co-occuring neotropical understory shrubs with different habitat preferences
}

\author{
Bettina M.J. Engelbrechta, ${ }^{a, *}, V$ irginia Velez ${ }^{b}$ and Melvin T. Tyree \\ a Technische Universität Darmstadt, Institut für Botanik, Schnittspahnstr. 3-5, 64287 Darmstadt, Germany \\ ${ }^{\mathrm{b}}$ Smithsonian Tropical Research Institute, P.O. Box 2072, Balboa, Panama \\ ${ }^{\mathrm{c}}$ USDA Forest Service, Aiken Forestry Sciences Laboratory, P.O. Box 968, South Burlington, VT 05402, USA
}

(Received 29 June 1999; accepted 14 December 1999)

\begin{abstract}
Whole plant hydraulic conductance was measured for two co-occuring neotropical rainforest understory shrub species of the genus Piper, which differ in their habitat preference with respect to soil moisture: P. trigonum is restricted to wet habitats, whereas $P$. cordulatum occurs in drier sites. Plants were grown under four treatments (two light conditions crossed with two watering regimes), representing the extremes of conditions in their natural habitat. The data showed significantly higher total hydraulic conductance and leaf specific conducance in the drought-avoiding species, $P$. trigonum, than in the drought-tolerant species $P$. cordulatum. The measured parameters also differed between growth treatments. The species differences in hydraulic conductance could be interpreted as adaptive in the respective species' habitat, and might thus be important in determining habitat preference and distribution of the two species.
\end{abstract}

hydraulic conductance / drought / Piper / tropical rainforest / understory shrub

Résumé - Conductance hydraulique de deux arbustes néotropicaux du sous étage ayant des habitats préférentiels. La conductance hydraulique de la plante entière a été mesurée pour deux espèces arbustives du genre Piper du sous étage d'une forêt néotropicale. Ces espèces différent par leur adaptation à l'humidité du sol : P. trigonum est localisé dans les habitats humides, alors que $P$. cordulatum se rencontre dans les zones sèches. Les plants ont été soumis à quatre traitements (deux conditions d'éclairement combinées avec deux régimes hydriques), représentant les conditions extrêmes de leurs habitats naturels. Les résultats montrent une conductance hydraulique et une conductance spécifique des feuilles significativement plus élevées pour l'espèce évitant la sécheresse, $P$. trigonum, par rapport à l'espèce tolérant la sécheresse, $P$. cordulatum. Les paramètres de croissance mesurés diffèrent aussi selon les traitements. Les différences de conductance hydraulique entre espèces peuvent être interprétées comme une adaptation aux conditions respectives de l'habitat, et peuvent être alors un facteur important dans la préférence pour l'habitat et la répartition des deux espèces.

conductance hydraulique / sécheresse / Piper / forêt tropicale / arbuste de sous étage

*Correspondence and reprints

Tel. 507-272-2124; Fax. 507-272-3065; e-mail: engelbrb@bci.si.edu 


\author{
Abbreviations \\ $K$ : hydraulic conductance $\left(\mathrm{kg} \mathrm{MPa}^{-1} \mathrm{~s}^{-1}\right)$, \\ $R$ : hydraulic resistance, $\left(\mathrm{MPa} \mathrm{s} \mathrm{kg}^{-1}\right)$, \\ $T R$ : transpiration rate (= evaporative flux density, \\ $\mathrm{kg} \mathrm{s}^{-1} \mathrm{~m}^{-2}$ ), \\ $L A$ : leaf area $\left(\mathrm{m}^{2}\right)$, \\ $K_{\mathrm{LA}}$ : leaf specific conductance $\left(\mathrm{kg} \mathrm{MPa}^{-1} \mathrm{~s}^{-1} \mathrm{~m}^{-2}\right)$, \\ $P$ : pressure $(\mathrm{MPa})$, \\ $\Delta P$ : pressure drop $(\mathrm{MPa})$, \\ $F$ : flux $\left(\mathrm{kg} \mathrm{s}^{-1}\right)$, \\ $\Psi$ : water potential (MPa), \\ the suffixes root, shoot, stem, leaves, meristem, plant \\ stand for the $K$ or $R$ of the respective organ or the whole \\ plant.
}

\section{INTRODUCTION}

The structure of the plant hydraulic system - the hydraulic architecture - can potentially limit water flow through plants and therefore restrict their water balance, gas exchange and growth [17]. Consequently, differences in hydraulic architecture might help to explain species habitat preferences with regard to soil moisture.

The water conducting system of plants should on one hand be built so that it allows for high water flow rates, high levels of stomatal opening, high transpiration and thus high carbon assimilation rates. On the other hand, it should be built, so that xylem embolism is avoided, even when water potentials get very negative, e.g. under drought conditions. An evolutionary trade-off between hydraulic conductivity and vulnerability to xylem embolisms has been proposed [28, modified by 16]. The outcome of this trade-off should reflect the ecology of the species, with plants occurring at moist microsites mainly optimizing water conductance, and plants at dry sites optimizing the avoidance of drought induced embolisms.

We studied two coexisting congeneric understory shrubs from the highly diverse pantropical genus Piper: $P$. trigonum C. DC. is restricted to wet rainforests or very moist microsites such as ravines, whereas $P$. cordulatum C. DC. is abundant in forests subjected to a pronounced dry season and tolerates relatively dry microsites, such as hilltops [7].

The hydraulic conductance of the two species grown under different light and soil moisture conditions was measured, to determine if the species with different habitat preference have different characteristics of their hydraulic architecture. And to see if differences in hydraulic architecture among species might explain their habitat preferences. We hypothesized that P. trigonum, the species occurring in wetter habitats, has higher hydraulic conductance than $P$. cordulatum, the species from drier habitats, reflecting structural optimization of the hydraulic system for water conductance rather than avoidance of xylem embolisms.

A number of studies have focused on the hydraulic architecture of the shoots of large woody tropical plants (e.g. review [17]). Information about the hydraulic architecture of entire tropical plants, and particularly about shade tolerant shrubs and their juvenile state is practically missing. The recent development of a high-pressure flowmeter [20, 27] now allows the rapid and accurate measurement of the conductance of the entire hydraulic system of small plants.

\section{METHODS}

We studied two understory shrubs that co-occur in the semi-decidious forest of Barro Colorado Island (BCI), Panama (9 $\left.9^{\prime} \mathrm{N} ; 79^{\circ} 51^{\prime} \mathrm{W}\right)$ : Piper trigonum C. DC. (previously known as $P$. arieianum C. DC.), and $P$. cordulatum C. DC. Cuttings from both species were grown under moderately shady conditions for 6 months. Plants of the same size (about $50 \mathrm{~cm}^{2}$ leaf area) were then transplanted into pots (volume: 2 l) with a mixture of soils from old-growth forest on BCI (upper $25 \mathrm{~cm}$ ) and were transferred to the experimental treatments in the shade house under clear plastic cover on BCI. The experiment was conducted in the dry season from January through April 1996 for 110 days.

\subsection{Experiment}

Three individuals of each species were grown under four different conditions: Two light conditions (high/low) crossed with two watering regimes (wet, dry).

The light conditions were chosen to represent extreme situations in the forest habitat of the plants: light conditions in the dark understory under a closed canopy layer [7], and in a gap of approximately $14 \mathrm{~m}$ diameter [3]. Neutral shade cloth was used to achieve the low light condition, the high light condition was full available light in the shade house, situated at the edge of a large forest clearing. Light intensities were measured on 5 days with different light regimes with quantum sensors (LI-COR 190 SB, LI-COR Inc, Lincoln, Nebrasca, USA) connected to a data logger (LI-1000, LI-COR Inc, Lincoln, Nebrasca, USA), and compared to above canopy light measurements on a nearby tower (data courtesy of the Smithsonian Environmental Research 
Program). Low light conditions were $0.2 \pm 0.01 \%$ of the light reaching the canopy, and high light conditions were $8.0 \pm 0.36 \%$.

The moisture conditions also represented the extremes experienced by the species. These range from soils near water holding capacity to wilting over several weeks in strong, but not unusual dry seasons (personal observation). The plants were either kept in soil near water holding capacity through watering them daily, or they grew not irrigated, until plants of both species reached permanent wilting point (sensu [1]) after about 7 weeks: The plants were strongly wilted and did not recover overnight without additional watering. For the remainder of the experiment, plants were kept at this level, by adding the approximate amount of water they lost every day (measured as whole plant transpiration, see below). This way the plants could be kept at a functionally defined level of water stress, without dying. Gravimetric soil water content of the upper $5 \mathrm{~cm}$ of soil in the pots was determined weekly. Significant differences between the watering regimes developed in the forth week of the experiment. It dropped to $30-35 \%$ dry weight in the dry treatment compared to $60-70 \%$ in the wet treatment. The soil water content stayed slightly higher under low than under high light conditions.

\subsection{Measurements}

Hydraulic conductance $(K)$ of the plants was measured using a high-pressure flowmeter (HPFM) as described in Tyree et al. (1995). Hydraulic conductance was measured on whole shoots, the stems without leaves and the roots. Hydraulic conductance of the roots was measured in a transient measurement with a rapid increase of the applied pressure. Shoot and stem conductance were measured at "quasi-steady-state" with a constant pressure of about $0.5 \mathrm{MPa}$. Flow rate was monitored until approximately constant. To determine stem and leaf conductance, an additional conductance measurement of the stem was made after cutting off the leaves. Conductances measured with this method are near maximum values, because xylem embolisms are greatly reduced at these high pressures.

Whole plant transpiration $(T R)$ was measured as gravimetric water loss, by repeatedly weighing (on a top loading balance to $\pm 0.01 \mathrm{~g}$ ) the plants in the pots, with the pots thoroughly isolated from evaporation by plastic bags. We used daytime transpiration (6.30 a.m. 6.30 p.m.) for further calculations. Plant leaf area $(L A)$ and stem diameter were measured as references for scaling of plant conductance. Plant leaf area was determined biweekly throughout the experiment, by measuring the area of outlines of the leaves (LI-3000 Portable Area Meter, LI-COR Inc., Lincoln, Nebrasca, USA). The largest leaf area the plants reached during the course of the experiment was used for further calculations. It was mostly reached about two weeks before the end of the experiment, because of abcission of some leaves immediately prior to the end of the experiment. Stem diameter was measured with a dial caliper (to $\pm 0.01 \mathrm{~mm}$ ) in the middle of the lowest internode. One $P$. cordulatum individual from dark, dry conditions died before the end of the experiment, and could not be included in the measurements.

\subsection{Calculations}

Conductance of the plant hydraulic system may vary between plant organs (e.g. $[17,19])$. To evaluate the role of the different organs, we examined resistances $(R, \mathrm{MPa}$ $\mathrm{s} \mathrm{kg^{-1 }}$ ), because resistances in series are additive. Resistance is the reciprocal of the plant conductance.

$$
\begin{gathered}
R=1 / K \\
R_{\text {plant }}=R_{\text {shoot }}+R_{\text {root }},
\end{gathered}
$$

where

$$
R_{\text {shoot }}=R_{\text {stem }}+R_{\text {leaves }} \text {. }
$$

Plant hydraulic conductance $\left(K, \mathrm{~kg} \mathrm{MPa}^{-1} \mathrm{~s}^{-1}\right)$ was calculated from the HPFM measurements as:

$$
K=F / \Delta P
$$

where $F$ is the flow through the respective organ, and $P$ is the applied pressure. Root, shoot and stem conductance was calculated accordingly.

Plant conductance was scaled to a structural and a functional parameter of the plant: leaf area $(L A)$ and transpiration $(T R)$, respectively. Leaf specific conductance $\left(K_{\mathrm{LA}}, \mathrm{kg} \mathrm{s}^{-1} \mathrm{MPa}^{-1} \mathrm{~m}^{-2}\right.$ ) was calculated as:

$$
K_{\mathrm{LA}}=K_{\text {plant }} / L A_{\text {plant }} .
$$

$K_{\mathrm{LA}}$ describes the potential of the xylem system to supply the leaf area of the plant with water. Leaf specific conductance is conventionally used to relate the conductance of a stem section to the leaf area it supplies [17]. We modified it to describe the hydraulic sufficiency of the whole plant.

By relating plant conductance to whole plant transpiration $\left(T R, \mathrm{~kg} \mathrm{~s}^{-1} \mathrm{~m}^{-2}\right)$, we calculated the pressure drop in the plant.

$$
\Delta P=T R / K_{\mathrm{LA}}=\Psi_{\text {soil }}-\Psi_{\text {leaf }} .
$$


The pressure drop in the plant is the difference between the water potential at the site of water absorption in the root $\left(\Psi_{\text {soil }}\right)$ and at the site of water loss in the leaf $\left(\Psi_{\text {leaf }}\right.$; more negative). The higher the pressure drop, the lower is the efficiency of the hydraulic system to supply the leaves with the amount of water they are actually loosing in transpiration.

\subsection{Analysis}

The data were analysed in an ANOVA with light and water treatments as fixed factors. To conform with the requirement of equal variances, all data were log transformed prior to analysis. We introduced basal stem diameter as an additional measure of plant size as a covariable in the analysis to account for the possibility that differences between species and growth conditions were due to ontogenetic dissimilarities (i.e different size; [6]). However, because stem diameter never had a significant effect, all data presented are calculated without this covariable. Statistical analysis were calculated with DataDesk 4.0. (Data Description Inc., Ithaca, U.S.A.).

\section{RESULTS}

The highest hydraulic resistance of the plants was in the root, to which more than half of the total resistance could be attributed in all plants except $P$. cordulatum under dry high light conditions, which had a slightly, but not significantly lower root resistance. Above-ground resistance accounted for the remaining $45 \%$ of the resistance, with stems and leaves contributing varying amounts. Differences between the resistance the plant organs - roots, stem and leaves - imposed were highly significant ( $p<0.0001$; figure 1).

Total plant hydraulic conductance was significantly higher in $P$. trigonum than in $P$. cordulatum (figure 2 ). It also varied with growth conditions, being greater in high than in low light conditions. There was a significant light $\times$ moisture interaction (table I), resulting in much more pronounced differences between the two light treatments under moist than under dry conditions.

Leaf specific conductance was again different for the two species and affected by the growth conditions, with similar trends as for whole plant conductance (figure $3 A$ ). Under all growth conditions it was about 1.4 times higher in $P$. trigonum than in $P$. cordulatum. Because both species had very similar leaf areas in each growth condition (figure $3 B$ ) this difference was almost entirely due to the differences in conductance. The highest values of $K_{\mathrm{LA}}$ in both species were reached in the high light, moist condition, with $K_{\mathrm{LA}}$ under all other growth conditions being considerably lower. Stem diameter did not have any significant effect on leaf specific conductance $(p>>0.05)$, including stem diameter as a covariable did not change the effect of species or growth conditions on $K_{\mathrm{LA}}$.

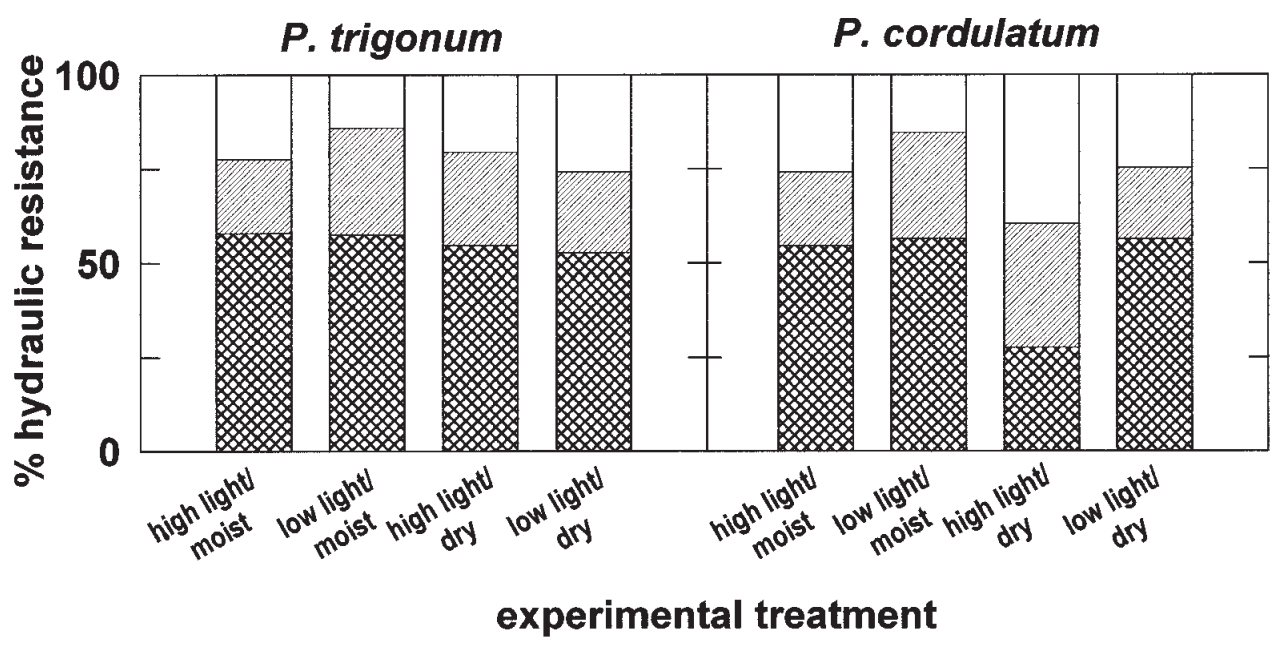

Figure 1. Percentage hydraulic resistance of roots, stems and leaves in $P$. trigonum and $P$. cordulatum grown under different light and soil moisture conditions. The signatures are: open: leaves; hatched: stems; cross-hatched: roots. The data are averages, $n=3$, except in $P$. cordulatum under dark, dry conditions $n=2$. 
Table I. Results of ANOVAs for variables describing plant hydraulic architecture and transpiration: whole plant conductance $\left(K_{\mathrm{plant}}\right.$; $\left.\mathrm{kg} \mathrm{s}^{-1} \mathrm{MPa}^{-1}\right)$, leaf specific conductance $\left(K_{\mathrm{LA}} ; \mathrm{kg} \mathrm{s}^{-1} \mathrm{MPa}^{-1} \mathrm{~m}^{-2}\right)$, transpiration $\left(T R ; \mathrm{kg} \mathrm{s}^{-1} \mathrm{~m}^{-2}\right)$ and pressure drop $(\Delta P ; \mathrm{MPa})$. Given are the $p$-values, n.s. stands for not significant at the 5\% level. $n=3$, except in $P$. cordulatum under dark, dry conditions: $n=2$. All data were $\log$ transformed prior to calculations.

\begin{tabular}{lcccccc}
\hline variable & \multicolumn{2}{c}{ factor } & & & \\
& species & light & moisture & light $\times$ species & moisture $\times$ species & light $\times$ moisture \\
\hline $\log \left(K_{\text {plant }}\right)$ & $<0.05$ & $<0.001$ & n.s. & n.s. & n.s. & $<0.01$ \\
$\log \left(K_{\mathrm{LA}}\right)$ & $<0.05$ & n.s. & n.s. & n.s. & n.s. & $<0.005$ \\
$\log (T R)$ & n.s. & $<0.0005$ & $\leq 0.0001$ & n.s. & n.s. & n.s. \\
$\log (\Delta P)$ & n.s. $(0.06)$ & n.s. & $<0.0005$ & n.s. & n.s. & $<0.005$ \\
\hline
\end{tabular}

There was a trend towards higher pressure drop, $\Delta P$, in $P$. cordulatum than in $P$. trigonum (figure $4 A$ ) but the difference was not significant $(p=0.057)$. Transpiration on a leaf area basis was not different between the two species, but depended strongly on growth conditions (figure $4 B$ ). It was about 3.5 times higher in the high light combined with moist soil treatment, than under low light, water stressed conditions. Under moist conditions the $\Delta P$ was higher than under drying conditions, indicating that the actual hydraulic sufficiency was lower in moist conditions. This was true, despite the higher leaf specific conductance in moist than in dry conditions under high light. The pressure drop was the highest under moist/low light conditions, a consequence of the fact that conductance was the lowest in these growth

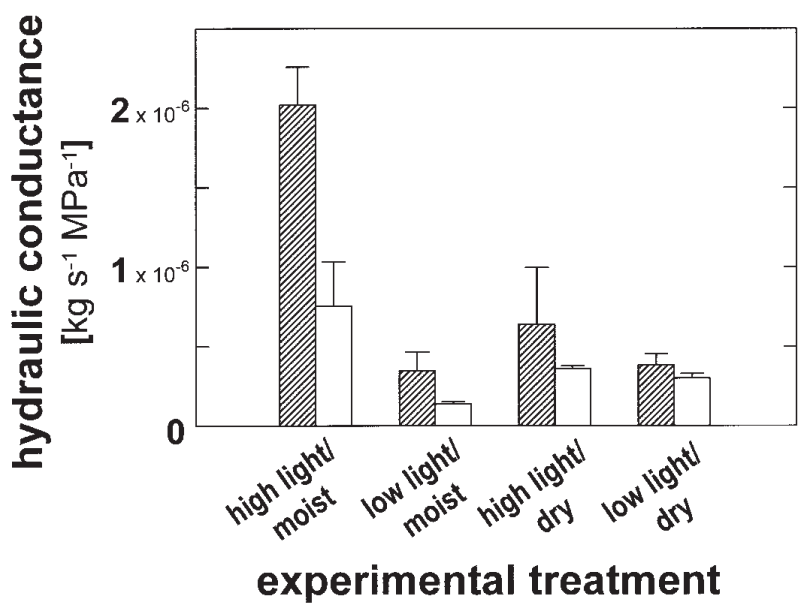

Figure 2. Hydraulic conductance of the entire hydraulic system of $P$. trigonum (hatched bars) and P. cordulatum (open bars) under different growth conditions. The data are averages and standard errors. $n=3$, except in $P$. cordulatum under dark, dry conditions: $n=2$. conditions, coupled with moderately high transpiration rates.

\section{DISCUSSION}

There were significant and clear differences in the hydraulic conductance of the two species: P. trigonum the species preferring moister habitats - had a higher

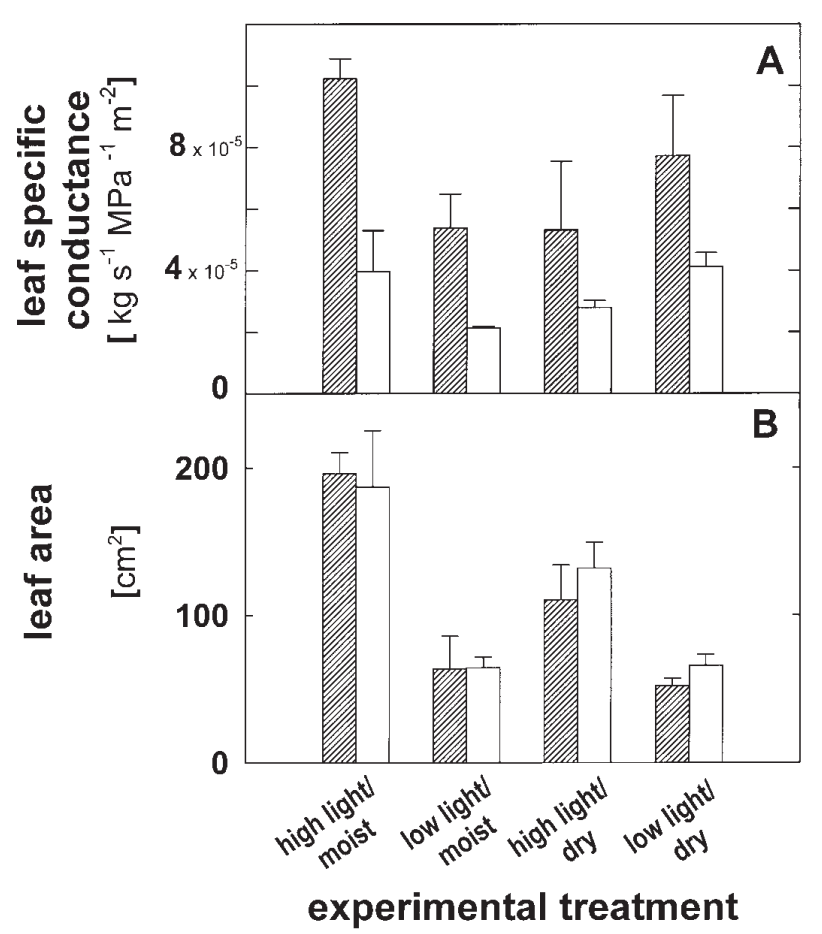

Figure 3. Leaf specific conductance (A) and leaf areas (B) of $P$. trigonum and $P$. cordulatum under different growth conditions. For details see figure 2. 


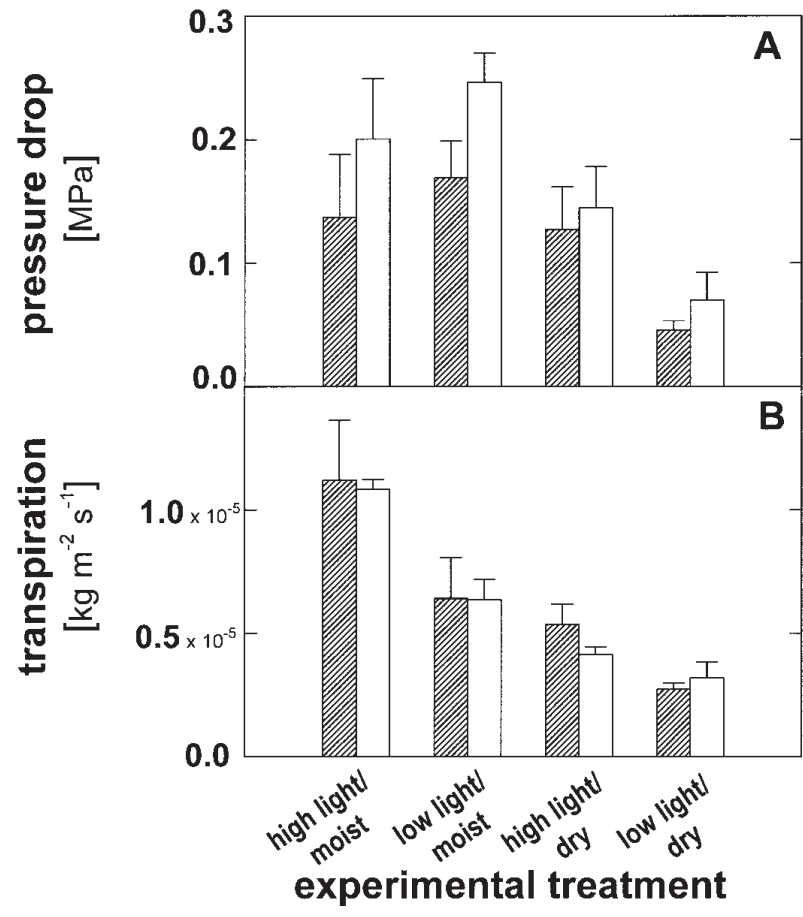

Figure 4. Pressure drop (transpiration per hydraulic conductance, A) and transpiration (B) of P. trigonum and P. cordulatum under different growth conditions. For details see figure 2 .

absolute plant conductance and a higher leaf specific conductance. There was also a (non significant) trend for lower $\Delta P$ in $P$. trigonum. Thus, $P$. trigonum was more efficient conducting water in its hydraulic system, and more efficient to supply its leaf area, the potentially transpiring area with water. Both species reacted in the same way to different growth conditions, and the amount of plasticity for conductance and leaf specific conductance in the range of growth conditions the plants were exposed to, was the same in both species. The hydraulic system of the species occurring in moist habitats and of the plants under high light/wet conditions was more efficient in supplying their leaf area, the potentially transpiring area, with water than the species occurring in drier habitats and plants under dry conditions. The resulting slightly lower $\Delta P$ in $P$. trigonum indicate, that at a given soil water potential, the leaf water potential did not have to be as negative as in $P$. cordulatum to sustain transpiration (Eq. 6). The pressure drop from equation (6) does not include the $\Delta P$ from the "bulk soil" to the root surface. It is difficult to compute without knowledge of soil hydraulic conductance and total root surface areas, neither of which was measured in this study. However, if we assume equal root surface areas for both species in each treatment, then we can conclude, that $\Delta P$ from the bulk soil to the root surface was the same, because transpiration rates for both species were approximately equal under each growth condition and the soil types were identical.

The hydraulic system of $P$. trigonum was built for high hydraulic conductance, supporting high transpiration rates. This seems consistent with current notions that plant water use is limited by rhizosphere and xylem conductance, i.e., that liquid-phase conductance limits maximal stomatal conductance $[15,26]$. The ability to support high transpiration rates allows the plant to have high stomatal conductances, which in turn permit high assimilation rates. Additionally, a high hydraulic conductance value will promote maximal values of $\Psi$ meristem both during day and night. Rapid growth is promoted when growing meristems are not water stressed. In habitats, where water is not a limiting factor (for most of the time), optimization for high hydraulic conductance therefore seems to be ecologically advantageous. The drought adapted species $P$. cordulatum had a considerably lower conductance and leaf specific conductance than P. trigonum. Recently Nardini and Tyree (1999) surveyed the hydraulic conductance of 7 Quercus species with different habitat preferences with respect to soil moisture. They also found a higher $K_{\mathrm{LA}}$ in the four water-demanding species compared to the drought adapted species. In dry habitats where growth is usually slow because of limited water availability, the ability to tolerate drought may be more important than the ability to transport water rapidly. There, it might by more adaptive to optimize for avoidance of embolisms than for high hydraulic conductance $[19,20]$. Hence, plants in dry habitats need invest less carbon into shoot conductance. Some arid zone species may also benefit from a higher ratio of carbon investment in roots versus shoots. However, for the Piper species we studied, there was no species difference in root-shoot-ratio [7].

Most studies of the hydraulic conductance of tropical plants focused on stems (e.g. reviewed by [17], [8, 11, $10,18,29,30]$. However, root resistance can contribute half or more of the whole plant hydraulic resistance, and leaf resistance can also make up a considerable percentage of the total plant hydraulic resistance. In Palicourea guanensis (Rubiaceae), a tropical shrub or small tree, root resistance approximately equaled shoot resistance, which in turn was contributed at about equal parts by leaf resistance and vascular resistance to water flow in stems [20]. In seedlings of 5 species of tropical trees root resistance contributed between $30 \%$ and $60 \%$ to whole plant resistance [23]. Thus, whole plant conductances are considerably lower than just stem conductance. As a 
consequence, leaf specific conductances get lower when considering the whole plant, estimates for pressure gradients increase and calculated leaf water potentials necessary to support transpiration get more negative. To assess the role the water conducting system of the plant plays for whole plant water relations, assimilation rates and for its ecology it is therefore crucial not only to consider stem hydraulic properties, but to consider the hydraulic architecture of the whole plant.

Most comparitive studies of hydraulic architecture have stressed the role of xylem anatomy in explaining differences in xylem conductance. Studies investigating wood anatomy generally found greater xylem vessel diameters in species from moister than from drier areas. In the chaparral flora of California, the flora of South Western Australia and in a comparison between a Mexican wet rain forest and a dry forest, species occurring in moister sites generally had the larger xylem vessel diameters and longer vessels $[2,4,5]$. The same trend was found within some species from the genus Quercus along a climatic gradient in NE Spain [24]. Nevertheless, xylem resistance of roots and shoots may account for only $20-30 \%$ of the total plant hydraulic resistance. Nonvascular resistance of roots and leaves may prove to be rather more important in determining the whole plant resistance to water flow in many species (e.g. [9, 13, 27]). There have been reports of large differences in root and leaf resistance to water flow between tropical species [22, 23], which may lead to considerable variation in plant hydraulic resistance that is independent of their vascular anatomy.

The two species within the same genus, and thus subjected to the same phylogenetic constraints, had markedly different conductances. The differences in hydraulic conductance could be interpreted as adaptive with respect to soil moisture regimes in the habitat, where each of the species occurs. This is quite remarkable, since differences between the habitat preferences are relatively slight compared to the full range of soil moistures and water vapour deficits plants can be exposed to (e.g. desert compared to understory rainforest plants). Both species occur in the understory of rainforests, a habitat with continuously high relative humidities, and exposed to relatively small temperature changes [25]. Furthermore, the difference in rainfall between the forests where the respective species are among the most common Piper species in the understory, do not differ that much when compared to the full range of rainfall regimes found in tropical lowland forests [7, 14]. Even comparably small environmental differences in moisture regimes may therefore strongly favour plants with different strategies in hydraulic architectures.

\section{CONCLUSIONS}

We found considerable differences between the hydraulic conductance of $P$. trigonum and $P$. cordulatum. These differences could be interpreted as enabling $P$. trigonum to be more effective in supporting high transpiration rates that are necessary to achieve high assimilations rates under conditions of ample water supply and relatively high light, than $P$. cordulatum. They may also allow for higher $\Psi_{\text {meristem }}$ values in P. trigonum promoting high growth rates. On the other hand it can be speculated that the lower conductance in $P$. cordulatum is correlated with lower vulnerability to xylem embolism, which would enable this species to be more successful than $P$. trigonum under conditions where water is limiting. These results reflect the conditions where both species are encountered in the field: $P$. trigonum occurs in very wet areas or microsites, and, besides being a successful and locally abundant understory species, has the ability to invade rather open areas, whereas, in contrast, $P$. cordulatum is the most abundant in seasonally dry habitats and in microsites that get rather dry. We can conclude that hydraulic conductance may play an important role in determining the species habitat preference.

Acknowledgements: We thank Nefertaris Daguerre for technical assistance in the experiment. The Smithsonian Tropical Research Institute, Panama, provided logistic support during the course of the project. The work was supported by the German Academic Exchange Service (DAAD) and by the U.S. Department of Agriculture, Forest Service through cooperative study agreements with the Smithsonian Tropical Research Institute.

\section{REFERENCES}

[1] Briggs J.L., Shantz H.L., The wilting coefficient and its determination, Bot. Gaz 53 (1913) 20-37.

[2] Barajas-Morales J., Wood structural differences between trees of two tropical forests in Mexico, Iawa Bull. (NS) 6 (1985) 355-364.

[3] Canham C.D., Denslow J.S., Platt W.J., Runkle J.R., Spies T.A. White P.S., Light regimes beneath closed canopies and tree-fall gaps in temperate and tropical forests, Can. J. For. Res. 20 (1990) 620-631.

[4] Carlquist S., Hoekman D.A., Ecological wood anatomy of the woody southern California flora, Iawa Bull. (NS) 6 (1986) 319-347.

[5] Carlquist S., Ecological factors in wood evolution: a floristic approach, Am. J. Bot. 64 (1977) 887-896. 
[6] Coleman J.S., Connaughay K.D.M., Ackerly D.D., Interpreting phenotypic variation in plants, Tree 9 (1994) 187 191.

[7] Engelbrecht B.M.J., Ökologie und Ökophysiologie von koexistierenden Piper-Arten im Unterwuchs tropischer Regenwälder, Doktorarbeit, Technische Universität Darmstadt, 1998.

[8] Ewers F.W., Fisher J.B., Fichtner K., Water flux and xylem structure in vines. in: Putz F.E., Mooney H.A. (Eds.), The biology of vines, Cambridge University Press, Cambridge, 1991, pp. 127-160.

[9] Frensch J., Steudle E., Axial and radial hydraulic resistance to roots of maize (Zea mays L.), Plant Physiol. 91 (1989) 719-726.

[10] Patiño S., Tyree M.T., Herre E.A., Comparison of hydraulic architecture of woody plants of differing phylogeny and growth form with special reference to free-standing and hemi-epiphyte Ficus species from Panama, New Phytol. 129 (1995) 125-134.

[11] Machado J.-L., Tyree M.T., Patterns of hydraulic architecture and water relations of two tropical canopy trees with contrasting leaf phenologies: Ochroma pyramidale and Pseudobombax septenatum, Tree Physiol. 14 (1994) 219-240.

[12] Nardini A., Tyree M.T., Root and shoot hydraulic conductance of seven Quercus species, Ann. Sci. For. 56 (1999) 371-377.

[13] North G.B., Ewers F.W., Nobel P.S., Main root - lateral root junctions of two desert succulents: changes in axial and radial components of hydraulic conductivity during drying, Am. J. Bot. 79 (1992) 1039-1050.

[14] Richards P.W., The tropical rain forest, $2^{\text {nd }}$ edition, Cambridge University Press, Cambridge, 1996.

[15] Sperry J.S., Adler F.R., Campbell G.S., Comstock J.P., Limitation of plant water use by rhizosphere and xylem conductance: results from a model, Plant. Cell. Environ. 21 (1998) 347-359.

[16] Tyree M.T., Davis S.D., Cochard H., Biophysical perspectives of xylem evolution: is there a tradeoff of hydraulic efficiency for vulnerability to dysfunction? Iawa Bull. (NS) 15 (1994) 335-360.

[17] Tyree M.T., Ewers F.W., The hydraulic architecture of trees and other woody plants, New Phytologist. 119 (1991) 345-360.

[18] Tyree M.T., Ewers F.W., Hydraulic architecture of woody tropical plants. in: Mulkey S.S., Chazdon R.L., Smith
A.P. (Eds.), Tropical Forest Plant Ecophysiology, Chapman \& Hall, New York, 1996, pp. 217-243.

[19] Tyree M.T., Kolb K.J., Rood S.B., Patiño S., Vulnerability to drought-induced cavitation of riparian cottonwoods in Alberta: a possible factor in the decline of the ecosystem? Tree Physiol. 14 (1994) 455-466.

[20] Tyree M.T., Patiño S., Bennink J., Alexander J., Dynamic measurements of root hydraulic conductance using a high-pressure flowmeter in the laboratory and field, J. Exp. Bot. 46 (1995) 83-94.

[21] Tyree M.T., Snyderman D.A., Wilmot T.R., Machado J.-L., Water relations and hydraulic architecture of a tropical tree (Schefflera morototoni), Plant Physiol. 96 (1991) 11051113.

[22] Tyree M.T., Sobrado M.A., Stratton L.J., Becker P., Diversity of hydraulic conductance in leaves of temperate and tropical species: possible causes and consequences, J. Trop. For. Sci. 11 (1999) 47-60.

[23] Tyree M.T., Velez V., Dalling J.W., Growth dynamics of root and shoot hydraulic conductance in seedlings of five neotropical tree species: Scaling to show possible adaption to differing light regimes, Oecologia 114 (1998) 293-298.

[24] Villar-Salvador P., Castro-Díez P., Pérez-Rontomè C., Montserrat-Martí G., Stem xylem features in three Quercus (Fagaceae) species along a climatic gradient in NE Spain, Trees 12 (1997) 90-96.

[25] Windsor D.M., Climate and moisture availability in a tropical forest. Long-term records from Barro Colorado Island, Panama. Smithsonian Institution Press, Washington DC, 1990.

[26] Yang Y., Tyree M.T., Hydraulic resistance in the shoots of Acer saccharum and its influence on leaf water potential and transpiration, Tree Physiol. 12 (1993) 231-242.

[27] Yang S., Tyree M.T., Hydraulic architecture of Acer saccharum and A. rubrum: comparison of branches to whole trees and the contribution of leaves to hydraulic architecture, J. Exp. Bot. 45 (1994) 179-186.

[28] Zimmermann M.H., Xylem structure and the ascent of sap. Springer Verlag, Heidelberg, 1983.

[29] Zotz G., Tyree M.T., Cochard H., Hydraulic architecture, water relations and vulnerability to cavitation of Clusia uvitana Pittier: a C3-CAM tropical hemiepiphyte, New Phytol. 127 (1994) 287-295.

[30] Zotz G., Tyree M.T., Patiño S., Carlton M.R., Hydraulic architecture and water use of selected species from a lower montane forest in Panama, Trees 12 (1998) 302-309. 